\title{
The Effect of Trehalose in Inhibiting Liver Damage Via the Il-6 Pathway in Old Mice
}

\author{
Rabiatul aminah ${ }^{1}$, Arif Santoso ${ }^{1}$, Muh Husni Cangara ${ }^{1}$, Marhaen Hardjo ${ }^{1}$, Aminuddin \\ Aminuddin $^{2}$, Endy Adnan ${ }^{1}$ \\ ${ }^{1}$ Department of Biomedic, Post Graduate School, Hasanuddin Univesity, Indonesia \\ ${ }^{2}$ Department of Nutrition, Faculty of Medicine Hasanuddin University and Hasanuddin \\ Hospital, Indonesia
}

\begin{abstract}
Trehalose is a non-reducing disaccharide consisting of two glucose molecules linked by a 1-1 glycosidic bond. Trehalose can play a role in organ detoxification, antioxidant enzyme activity, reducing lipid peroxidation and reducing the secretion of inflammatory factors TNF-, IL-1 $\beta$, Il-6, thereby inhibiting liver damage. Because of its role, this study aims to determine the effect of trehalose administration on liver damage through the IL-6 expression pathway with experimental post-test design with control group design. This research was conducted using samples of old rats, namely Wistar rats (Rattus novergicus). The old rats used were 21 male species which were then divided into 3 groups, namely the old control group, the old rat group that was given sucrose, and the old rat group that was given trehalose. Then observed for 8 weeks, namely in March - May 2021 at the Faculty of Medicine, Hasanuddin University Makassar. The results obtained from the 3 groups showed a significant value that the administration of trehalose sugar in elderly mice had an effect on reducing the inflammatory factor IL-6 because it activated autophagy in macrophages thereby reducing cytokine production and vascular inflammation so as to be able to restore all aging mice to a level like observed in young mice. It is also known that aged rat liver, which is characterized by ER UPR activation and inflammatory signaling, decreases nicotinamide and UDP-N-acetylhexosamines, and reduces proteasome activity. Therefore, trehalose can be an effective therapeutic strategy against age-related disorders of proteostasis in the liver.
\end{abstract}

Keywords: Trehalose, Aging, Inflammation

Received : September 9, 2021

Received in Revised: September 29, 2021

Accepted: October 3, 2021

\section{Introduction}

In addition to its role in drug metabolism, the aging liver in the human liver is manifested by reduced blood volume and flow as well as cellular changes such as increased oxidative stress, decreased mitochondrial number and dysfunction, accelerated cellular aging, and decreased regenerative abilities. Aging is a risk factor for several liver diseases. IL-6 is another cytokine associated with obesity and insulin resistance, IL-6 also inhibits adipogenesis and decreases adiponectin secretion (Susantiningsih \& Mustofa, 2018) IL-6 ability to mediate mitochondrial beta-oxidation of fatty acids, increase hepatic triglyceride and cholesterol export, antioxidants, as well as their antiapoptotic effects on hepatocytes (Gavito et al., 2016). As for hepatic lipid metabolism, there is evidence that IL-6 affects opposite fatty acid pathways, namely degradation, and synthesis (Tonini et al., 2021; Tanner \& Alfieri, 2021; Zhang et al., 2021).

Trehalose is a non-reducing disaccharide consisting of two glucose molecules linked by a 1-1 glycosidic bond. When compared with sucrose, the level of sweetness of this sugar is about

Copyright @ 2021 , International Journal Papier Advance and Scientific Review, Under the license CC BY-SA 4.0

DOI: https://doi.org/10.47667/ijpasr.v2i2.112 
$45 \%$ and has amorphous properties at $100 \%$ without water. This sugar is effective in wound healing by protecting cells, especially cell membranes, from oxidative injury and drying. Mycobacterial CF (as a natural product containing trehalose) has the potential to kill tumor cells in guinea pigs and mice, and surface trehalose can also induce in vitro death of human hepatocellular carcinoma cells (Hep-G2 and HuH-7), humans, Colon carcinoma and gastric carcinoma (Moeini et al., 2020; Rezabakhsh et al., 2019).

Trehalose shows the ability to stabilize proteins and activate autophagy. Administration of trehalose reduces polyglutamine aggregates in the cerebrum and liver in transgenic mice with a Huntington's disease model through a mechanism involving partial stabilization of unfolded polyglutamine-containing proteins. Recent studies have shown that trehalose induces hepatocyte autophagy and reduces hepatocyte steatosis in response to a high-fructose diet (Pagliassotti et al., 2017). Although its biosynthesis in mammals is unknown, large amounts of trehalase, the enzyme that cleaves trehalose into two glucose molecules, are found in the small intestine, kidney, and liver of humans. Trehalose is said to be similar to glucose, so it is thought to be rapidly hydrolyzed to glucose by the enzyme trehalase. This study aimed to analyze the effect of trehalose administration on IL-6 expression and the degree of liver damage associated with aging in rats

\section{Methods}

This research is an experimental study on experimental animals with a post-test design with a control group design. The experimental animals used were 21 male Wistar (Rattus novergicus) rats which were divided into 3 groups, namely the old control group, the old rat group that was given sucrose, and the old rat group that was given trehalose and observed for 8 weeks.

This research will be conducted at the Faculty of Medicine, Hasanuddin University Makassar. Animal rearing and preparations were carried out at the Entomology Laboratory, Faculty of Medicine, Hasanuddin University Makassar. Immunohistochemical examination with IL6 antibody staining procedures and HE staining was carried out at the Anatomical Pathology Laboratory, Hasanuddin University Teaching Hospital, Makassar. The time of the research will be in March-May 2021. The research sample used was male Wistar rats (Rattus novergicus) for the old control group and the intervention group used male Wistar rats aged 12-18 months weighing between 200-400 grams in good condition characterized by active and healthy movements. The selection of 12 months of age was based on the maximum age of this strain, which is up to 3 years ( 36 months). The aging process begins at the age of 30 years in humans, and if it is estimated that the maximum age of humans is 90 years, then the aging process in rats which is analogous to humans begins at the age of 1 year (12 months), the selection of male Wistar rats (Rattus novergicus) in this study because it resembled humans.

To determine the size of the rat sample to be used, this study used the Federer formula, which is as follows:

$(\mathrm{t}-1)(\mathrm{n}-1)>15$

Description:

$\mathrm{t}=$ number of treatment groups

$\mathrm{n}=$ number of samples per group

Calculation:

$(3-1)(\mathrm{n}-1)>15$

$3 n-3>15$

Copyright $@$ 2021, International Journal Papier Advance and Scientific Review, Under the license CC BY-SA 4.0

DOI: https://doi.org/10.47667/ijpasr.v2i2.112 
$3 n>8$

$\mathrm{n}>6$

The ideal sample size according to the Federer formula calculation above is 6 rats/group. So the number of rats used in this study was 7 rats/group. thus the overall sample size was 21 which were divided into 3 groups. Inclusion Criteria: (1) Old rat age 12-18 months; (2) Weight 200 - 400 grams; (3) Mice move actively; (4) Physical condition is healthy and does not appear anatomically deformed

Exclusion Criteria: (1) Male Wistar rats (Rattus novergicus) were sick during the study; (2) Male Wistar rats (Rattus novergicus) died during the research; (3) Research Subject Permission. In carrying out this research, every action taken has obtained permission to be used as a research sample and is declared to meet the ethical requirements to be carried out from the Health Research Ethics Commission (KEPK) FK UH _RSPTN UH - Dr. Wahidin Sudirohusodo Hospital Makassar with Number: 242/UN4.6.4.5.31/PP36/2021

This study will pay attention to the ethical principles of research on experimental animals, namely 3R and 5F: (Yurista, Ferdian, and Sargowo, 2017)

\section{R (Refinement, Reduction, and Replacement)}

(1) Refinement aims to minimize pain, fear, and difficulty; (2) Reduction can minimize pain, fear, and distress by using fewer animals; (3) Replacement aims to minimize pain, fear, and distress by replacing "living animals that have a high level of consciousness" with "material insentient" that cannot experience pain, fear, or distress.

\section{F (Freedom)}

(1) Freedom from hunger and thirst; (2) Freedom from discomfort; (3) Freedom from pain, injury, and diseases; (4) Freedom from fear and distress; (5) Freedom to express natural behavior

\section{Work Procedures}

\section{Preparation of Experimental Animals}

The cage adaptation/acclimatization was carried out for 1 week. Male Wistar rats were given a standard diet/feed and given adequate drinking. The cages were cleaned every day to maintain a stable environment, the Wistar rats were placed in a room with sufficient air circulation and maintained at a standard room temperature $\left(28+2^{\circ} \mathrm{C}\right)$ with a humidity of $50 \%+10 \%$ and the room lights were set in a 12-hour dark cycle. and light 12 hours.

\section{Preparation of Sucrose Solution (sugar)}

Based on several references to the sucrose concentration used in previous studies, the concentration used was $2 \%$ (using the formula $\mathrm{M} / \mathrm{V} \times 100 \%$; where $\mathrm{M}$ is the mass of sucrose and $\mathrm{V}$ is the volume of water/day that will dissolve the sucrose). . And the daily water intake for male Wistar rats aged $>12-18$ months is $+40 \mathrm{ml} /$ day.

$2 \%=\mathrm{M} / \mathrm{V} \times 100 \% \rightarrow 2 \%=\mathrm{M} /(40 \mathrm{ml}) \times 100 \%$

$\mathrm{M}=0.8$ grams

Based on the above calculations, the dose of sucrose to be used is 0.8 grams.

So, 0.8 grams of sucrose (sugar) was dissolved in $40 \mathrm{ml}$ of distilled water, and autoclaved for +10 minutes to prevent infection and then put into the mice's drinking bottles. 


\section{Preparation of Trehalose Solution}

Based on several references to the concentration of trehalose used in previous studies, the concentration used is $2 \%$ (using the formula $\mathrm{M} / \mathrm{V} \times 100 \%$; where $\mathrm{M}$ is the mass of trehalose; and $\mathrm{V}$ is the volume of water/day that will dissolve the trehalose ). And the daily water intake for male Wistar rats aged $>12-18$ months is $+40 \mathrm{ml} /$ day.

$$
\begin{array}{r}
2 \%=\frac{M}{V} \times 100 \% \rightarrow 2 \%=\frac{M}{40 \mathrm{ml}} \times 100 \% \\
M=0,8 \text { gram }
\end{array}
$$

Based on the above calculations, the dose of trehalose to be used is 0.8 grams.

Thus, 0.8 grams of trehalose was dissolved in $40 \mathrm{ml}$ of distilled water, and autoclaved for +10 minutes to prevent infection, then put into the mice's drinking bottles.

\section{Intervention}

21 old rats (aged 12-18) were randomly divided into 3 groups with the same number $(n=7)$ in each group. group A. is an old control group that is given standard feed and drinks in moderation; group B is a group of experimental rats given standard feed and $2 \%$ sucrose solution, and group $\mathrm{C}$ was a group of experimental rats given standard feed and $2 \%$ trehalose solution which was put into a drinking bottle. This intervention was carried out for 8 weeks, and then terminated at week 8 for tissue sampling.

\section{Post-intervention (the sample collection)}

(1) Rats were anesthetized by placing cotton in a jar at the bottom, and cotton was moistened with $5 \mathrm{ml}$ of ether; then the rat was put into the jar and left for 5 minutes. After that, the rat was removed from the jar and confirmed to have been anesthetized; (2) Rats that have been anesthetized are then euthanized using the cervical dislocation technique, namely the head and tail of the rat are pulled in the opposite direction; (3) Mice that have died are necropsied for liver organ harvesting, first wetting the ventral part of the body with $70 \%$ saline/antiseptic alcohol to prevent hair from entering the tissue or sample; (4) Rats were placed on styrofoam in a dorsal lying position and the extremities were fixed using a needle; (5) The abdominal cavity is opened with an incision in the linea alba of the abdomen, and the abdominal cavity is opened; (6) After the abdominal cavity is open, the liver is taken; (7) The liver is then stored in $10 \%$ buffered formalin for the preparation of histopathological preparations at the Entomology Laboratory, Faculty of Medicine, Hasanuddin University; (8) After the procedure, the mice were buried in the ground.

\section{Hematoxylin-Eosin (HE) examination}

Following are the working steps before HE staining (tissue preparation); (1) Tissue that has been cut is inserted into the cassette and processed in a tissue processing machine (Tissue Automatics Processor); (2) Embedding Process (The processed tissue in the processing machine is blocked using liquid paraffin); (3) Cut the tissue in paraffin blocks using a microtome with a thickness of 3-4 m. (4) The band of tissue formed is dipped into the water bath; (5) Take the pieces of tissue with a slide and then drain; (6) Write the code on the slide according to the code listed on the paraffin block using a pencil; (7) Heat the slide on the Hot Plate for 1 hour; (8) Cool the slide and put it in the sliding basket; (9) Deparaffination (Xylol I, Xylol II, Xylol III) 5 minutes each; (10) Rehydrate (96\% Alcohol, 80\% Alcohol, 70\% Alcohol) for 5 minutes each; (11) Wash in running water for 5 minutes; (12) Soak with 
hematoxylin Mayer 7-10 minutes; (13) Wash in running water for 5 minutes; (14) Dip in eosin solution for 10 seconds; (15) Dehydration (70\% alcohol, $80 \%$ alcohol, $96 \%$ alcohol) every 5 minutes; (16) Clearing (Xylol I, Xylol II, Xylol III) 5 minutes each; (17) Dry the slide and then drip with Entelan and cover the deck glass; (18) Observe under a microscope.

\section{Immunohistochemical Examination}

(a) Tissue samples were processed in a standard way, put in paraffin, and cut into slices $4 \mathrm{um}$ thick, deparaffinized, and rehydrated in Phosphate Buffer Saline (PBS) solution; (b) Primary mouse polyclonal antibody IL-6 was diluted 1:100 with normal antibody diluent (Scitec brand) and incubated for 60 minutes at room temperature. Then rinsed with PBS for 5 minutes; (3) After that, Ultrateck Anti_Polivalent Biotinylated Antibody (brand Scytec) is added and left for 10 minutes. then rinsed with PBS for 5 minutes; (4) Add Aluratek HRP (horseradish peroxidase) for 10 minutes and rinse with PBS for 5 minutes; (5) For visualization, diaminobenzidine substrate chromogen solution (DAB, Brand Scytec) was used for 5 minutes. Finally, the slides were stained with hematoxylin, as a negative control, the aortic slices were carried out the same procedure without staining with primary antibodies and then observed using a light microscope.

\section{Operational Definition and Objective Criteria}

Old rats are male Wistar rats (Rattus novergicus), aged 12 -18 months, weighing 200-400 grams, and in good physical condition and do not appear anatomically deformed.

The standard feed used was AD 2 standard feed (Van der vour), which was given as much as $10 \%$ body weight, ie 20-25 grams/head/day for old rats. The composition of the van der vour feed was: Soybean meal, Bean, Palm meal, Corn, Palm oil, Premixec, Soluble dried grain, and Wheat Pollard and feed content: $20 \%$ protein, $7 \%$ fat, $15-20 \%$ fiber, $1 \%$ potassium, $0.8 \%$ phosphorus.

$2 \%$ sucrose solution is 0.8 grams of sucrose dissolved in $40 \mathrm{ml}$ of distilled water and then autoclaved for +10 minutes and put into a drinking bottle.

$2 \%$ trehalose solution is 0.8 grams of trehalose dissolved in $40 \mathrm{ml}$ of distilled water and then autoclaved for +10 minutes and put into a drinking bottle.

Table 1. Histopathological examination of HE staining by assessing the degree of liver damage.

\begin{tabular}{|l|l|}
\hline Score & Damage Rate \\
\hline Score 0 & There is no degeneration and necrosis in the observed section \\
\hline Score 1 & $\begin{array}{l}\text { There is 0-5\% degeneration and necrosis in the observed } \\
\text { section }\end{array}$ \\
\hline Score 2 & $\begin{array}{l}\text { There is 6-25\% degeneration and necrosis in the observed } \\
\text { section }\end{array}$ \\
\hline Score 3 & $\begin{array}{l}\text { There is 26-50\% degeneration and necrosis in the observed } \\
\text { section }\end{array}$ \\
\hline Score 4 & $\begin{array}{l}\text { There is more than 50\% degeneration and necrosis of the } \\
\text { observed site (severe damage) }\end{array}$ \\
\hline
\end{tabular}

Immunohistochemical examination is the method of staining using mouse antibody IL-6 as primary antibody and antibody labeled Hourse Radish Peroxidase (HRP). IL-6 expression is observed as brown color. 
The brown area appears due to the presence of the IL- 6 antibody with the antigen in the tissue. The observation will use a microscope with the use of 40x, 100x, and 400x and the appearance of the coloring is assessed in the form of (Zeng J,2017):

To assess the expression of IL-6, the following scores were used (Zeng j, 2017):

Intensity

Score 1: weak

Score 2: strong

Percentage

Score 0: 0\%

Score 1: $1-50 \%$

Score 2: $51-75 \%$

Score $3:>75 \%$

The results of the immunohistochemical assessment of the IL-6 expression score are the results of the formula below, which (N. Maulina, 2015):

Immunohistochemistry IL-6=Intensity x percentage

Score:

$0=$ no expression

$1-3=$ low expression

$>3$ = high expression

\section{Data Analysis}

All data were obtained using the SPSS for Windows program and analyzed with a significance level of $\mathrm{p}<0.05$. The research results will be presented descriptively and statistical analysis. Descriptive description of the assessment of IL-6 expression and histopathological features of the liver. The normality test of the data using Shapiro-Wilk with a significance value of $\mathrm{P}>0.05$ indicates the data is normally distributed or $p>0.05$ indicates the data is not normally distributed. One Way ANOVA statistical test is used if the data is normally distributed then the statistical test used is the Kruskal Wallis test. The Pearson correlation test is used if the data is normally distributed, while the Spearman correlation test is used if the data is not normally distributed. The results of the hypothesis test were stated to be significant if $\mathrm{P}<0.05$

\section{Results and Discussion}

\section{Characteristics of the Sample Overview}

This study is a study on the effect of trehalose in inhibiting liver damage through the IL-6 pathway in old mice that were carried out in March-May 2021.

Twenty-one rats were divided into 3 groups, group A was a negative control, B was given a $2 \%$ sucrose solution, while $\mathrm{C}$ was given a $2 \%$ trehalose solution. This intervention was carried out for 8 weeks, and then terminated at week 8 for tissue sampling.

Table 1. Characteristics of the research sample

\begin{tabular}{|c|c|c|c|c|c|c|c|}
\hline Group & \multicolumn{2}{|c|}{$\begin{array}{c}\text { Age } \\
\text { Mean } \pm \text { SD }\end{array}$} & \multicolumn{2}{|c|}{$\begin{array}{c}\text { Initial weight } \\
\text { Mean } \pm \text { SD }\end{array}$} & \multicolumn{2}{|c|}{$\begin{array}{c}\text { Final weight } \\
\text { Mean } \pm \text { SD }\end{array}$} & $\begin{array}{c}\text { Score } p \\
\text { (Initial } \\
\text { weight- Final } \\
\text { weight) }\end{array}$ \\
\hline A. Old Rat & 14.57 & \pm 1.13 & 228.57 & \pm 40.27 & 302.14 & \pm 28.050 & $0.018^{*} \mathrm{c}$ \\
\hline
\end{tabular}




\begin{tabular}{|c|c|c|c|c|c|c|c|}
\hline $\begin{array}{c}\text { B. sucrose } \\
\text { solution 2\% }\end{array}$ & 14.71 & \pm 1.11 & 242.28 & \pm 50.47 & 297.14 & \pm 52.768 & $0.063 \mathrm{c}$ \\
\hline $\begin{array}{c}\text { C. Trehalosa } \\
\text { solution 2\% }\end{array}$ & 14.42 & \pm 1.13 & 226.42 & \pm 47.16 & 291.85 & \pm 49.07 & $0.028^{*} \mathrm{c}$ \\
\hline Nilai p & \multicolumn{2}{|c|}{$0.621 \mathrm{a}$} & \multicolumn{2}{|c|}{$0.558 \mathrm{a}$} & \multicolumn{2}{|c|}{$0.912 \mathrm{~b}$} & \\
\hline
\end{tabular}

a Kruskall Wallis; $\mathrm{p}<0.05 ; *$ significant

b Oneway Anova; $\mathrm{p}<0.05 ; *$ significant

c Wilcoxon; $\mathrm{p}<0.05 ; *$ significant

Based on table 1 shows the characteristics of the research sample, namely age, initial body weight, and final bodyweight of the research sample. old mice $14.57 \pm 1.13,2 \%$ sucrose solution $14.71 \pm 1.11$ and trehalose $2 \%$ solution $14.42 \pm 1.13$. Based on the Kruskal Wallis statistical test, it showed $\mathrm{p}<0.05$, which means that there were significant differences in each research group. The body weight of old rats was $228.57 \pm 40.27,2 \%$ sucrose solution 242.28 \pm 50.47 , and $2 \%$ trehalose solution $226.42 \pm 47.16$. Based on the Kruskal Wallis statistical test, it showed $\mathrm{p}<0.05$, which means that there were significant differences in each research group. The final body weight of old rats was $302.14 \pm 28.05$, $2 \%$ sucrose solution $297.14 \pm 52.76$, and $2 \%$ trehalose solution 291.85 \pm 49.07 . Based on the Oneway ANOVA statistical test, it showed $\mathrm{p}<0.05$, which means that there were significant differences in each research group.

Weight gain before and after the study based on the Wilcoxon statistical test on old rats, and $2 \%$ trehalose solution showed a significance value of $\mathrm{p}<0.05$, which means that there was a significant difference in body weight gain in each group, whereas in the group with sucrose solution $2 \%$ showed a significance value of $p>0.05$, which means that there was no significant difference in weight gain in the group given $2 \%$ sucrose solution.

\section{Histopathological Observations}

The results of the histopathological observation of liver damage observed after the intervention can be seen in the following figure.

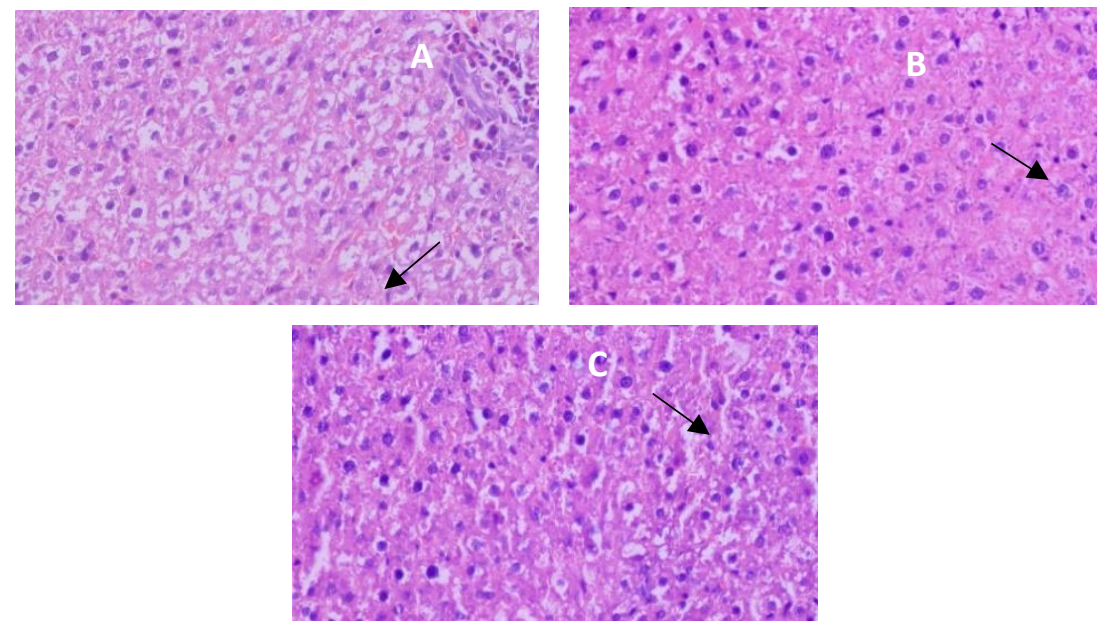

Figure 1. Histopathological description of liver damage in the form of hydrophilic degeneration (arrow), A negative control using old mice, B 2\% sucrose solution, C $2 \%$ trehalose solution 


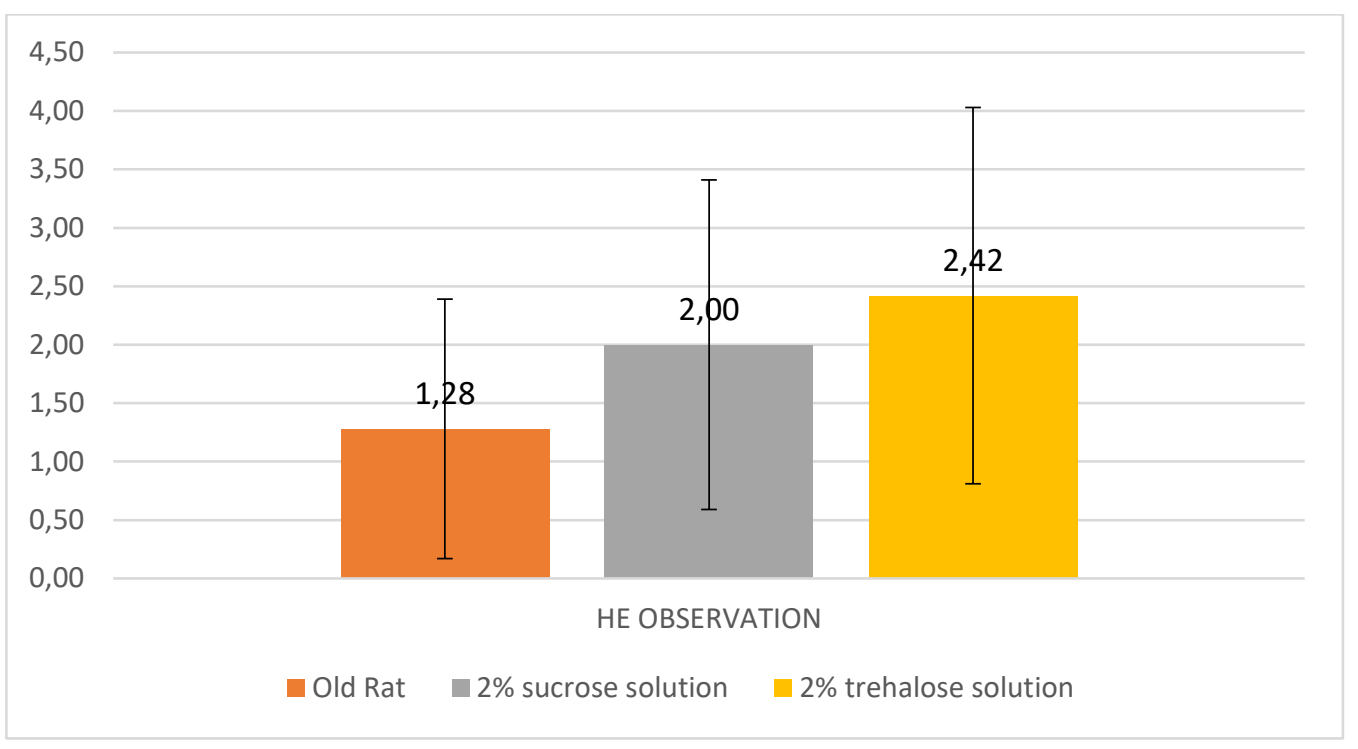

Figure 2. Graph of the average amount of liver damage on histopathological observations (HE)

Based on Figure 2 the graph of the average liver damage on histopathological observations (HE staining), C (2\% trehalose solution) showed an average of 2.42, in A (negative control using old mice) was 1.28 and B ( $2 \%$ sucrose solution) ie 2 .

Table 1. Average liver damage and different tests for all groups of histopathological observations

\begin{tabular}{|l|l|l|}
\hline Group & \multicolumn{2}{|l|}{$\begin{array}{l}\text { Pengamatan HE } \\
\text { Mean } \pm \text { SD }\end{array}$} \\
\hline Old rat & 1.28 & \pm 1.11 \\
\hline Sucrose solution 2\% & 2.00 & \pm 1.41 \\
\hline Trehalosa solution 2\% & 2.42 & \pm 1.61 \\
\hline Score p & $0.326 \mathrm{a}$ \\
\hline
\end{tabular}

Before carrying out statistical tests, normality and homogeneity tests were carried out first, namely normality using the Shapiro Wilk test and homogeneity using Levene's test. $p>0.05$ followed by a non-parametric statistical test. Based on table 1, the histopathological observations obtained normality and homogeneity tests of $p>0.05$ so that it was continued using parametric statistical tests using one way ANOVA and showed a significance value of $p>0.05(p=0.410)$ which means that there was no significant difference in liver damage from each group.

\section{Immunohistochemical Observations}
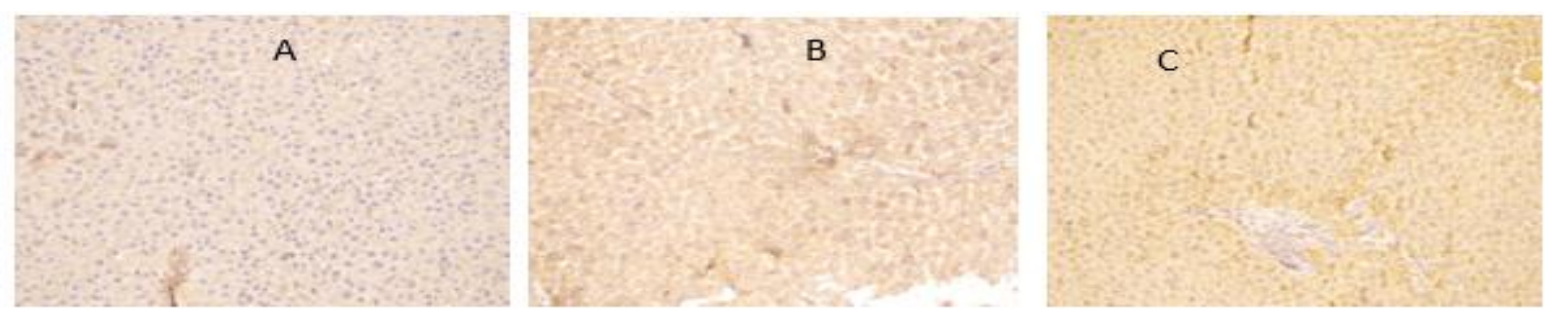

Figure 3. Immunohistochemical observations of IL-6, A negative control using old mice where the intensity is weak, the percentage is $51-75 \%$ high expression score. B $2 \%$ sucrose 
solution weak intensity, the percentage 51-75\% high expression score. C $2 \%$ trehalose solution weak intensity, the percentage is $51-75 \%$ with a high expression score

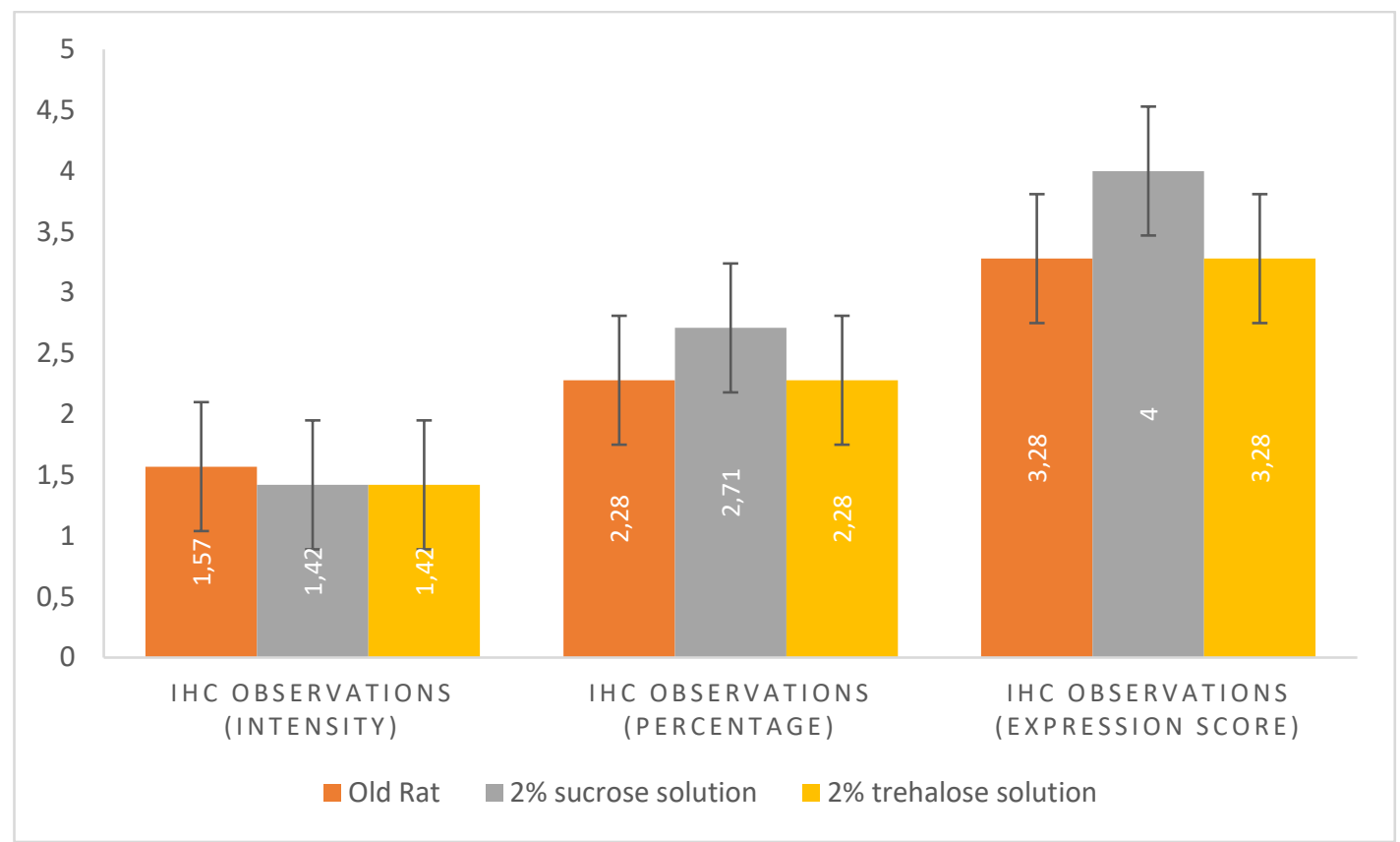

Figure 4. Graph of average IL-6 expression on immunohistochemical observations

\begin{tabular}{|l|l|l|l|l|l|l|l|}
\hline & \multicolumn{2}{|l|}{$\begin{array}{l}\text { IHC Observed } \\
\text { (intensity) }\end{array}$} & \multicolumn{2}{l|l}{$\begin{array}{l}\text { IHC Observed } \\
\text { (percentage) }\end{array}$} & $\begin{array}{l}\text { IHC Observed (IL- } \\
6 \text { score) }\end{array}$ & $\begin{array}{l}\text { IHC Observed } \\
\text { (expression score) }\end{array}$ \\
\hline Old rat & 1.57 & \pm 0.53 & 2.28 & \pm 0.75 & 3.28 & \pm 0.75 & high expression \\
\hline Sucrose solution 2\% & 1.42 & \pm 0.53 & 2.71 & \pm 0.48 & 4.00 & \pm 1.91 & high expression \\
\hline Trehalosa solution 2\% & 1.42 & \pm 0.53 & 2.28 & \pm 0.75 & 3.28 & \pm 1.60 & high expression \\
\hline Score p & $0.834 \mathrm{c}$ & $0.411 \mathrm{c}$ & $0.515 \mathrm{c}$ & \\
\hline
\end{tabular}

c Kruskall Wallis $\mathrm{p}<0.05$; *significant

Before carrying out statistical tests, normality and homogeneity tests were carried out first, namely normality using the Shapiro Wilk test and homogeneity using Levene's test. In immunohistochemical observations of IL- 6 expression, both the intensity, percentage, and final results, the IL-6 expression score showed a significance value of $p>0.05$ using the nonparametric Kruskal Wallis test, which means that there was no difference in the intensity, percentage, or score of IL-6 expression. meaning from each existing group.

Aging is associated with various morphological and functional changes. In the liver, aging is characterized by metabolic changes that contribute to hepatic steatosis, activation of inflammatory signaling pathways, impaired protein stability, and activation of protein quality control pathways such as the ER UPR. Oxidative stress and inflammation are the main mechanisms of the aging process that cause severe mitochondrial injury to liver DNA resulting in apoptosis. This inflammation results in autophagy activity by Th1 cytokines, such as TNF-, IL-1, and IL-6 which are both inductive and suppressive.

Trehalose is a natural disaccharide that can increase autophagy activity in various mammalian cells, including epithelial cells. A previous study evaluated the protective mechanism of trehalose against aging due to oxidative stress by induction of d-galactose in aged mice and found that trehalose activates downstream expression of target genes HO-1, NQO1, SOD, GSH, and CAT by promoting nuclear translocation of Nrf2 in the liver. This results in increased

Copyright @ 2021 , International Journal Papier Advance and Scientific Review, Under the license CC BY-SA 4.0

DOI: https://doi.org/10.47667/ijpasr.v2i2.112 
organ detoxification and antioxidant enzyme activity, reduced lipid peroxidation, and decreased secretion of the inflammatory factors TNF-, IL-1 $\beta$, Il-6. These inflammatory cytokines are associated with ROS and promote activated NF-B to translocate to the nucleus and regulate the expression of pro-inflammatory genes such as iNOS and COX2, which are involved in inflammation and response, fibrosis, apoptosis, and acute-phase responses leading to tissue damage and inflammation organ.

This study aims to determine the effect of trehalose administration on liver damage through the IL-6 expression pathway in old rats. As for the results of immunohistochemical observations of IL-6 expression for intensity, it was seen that the scores of groups B and C were lower than group A, for the percentage of IL-6, group C given trehalose and group B given sucrose had a lower score than group, while for IL-6 expression, groups A, B, and C had higher scores. However, this difference between groups was not significant because the test results showed a significant value. The lower group C scores on the percentage and expression of IL-6 indicated that the administration of trehalose sugar in elderly mice affected decreasing the inflammatory factor IL-6.

These results are in line with the study by which found that administration of trehalose sugar would activate autophagy in macrophages thereby reducing cytokine production and vascular inflammation. In addition, research also showed an increase in cell viability due to the addition of trehalose. Prevention of cell death by trehalose is due to increased autolysosomal formation and autophagy flux. Although this study could not identify the main target of trehalose, it showed that trehalose effectively reduced ER UPR activation and inflammatory signaling in aged mice thereby preventing an increase in several liver injury indices in aged mice.

This study also demonstrated that aged mouse livers are characterized by ER UPR activation and inflammatory signaling, decreased nicotinamide and UDP-N-acetyl-hexosamines, and reduced proteasome activity. Trehalose was able to restore all of these changes to levels as observed in young mice. Trehalose also increased AMPK phosphorylation and LC3B-II accumulation in the liver of aged mice. Therefore, trehalose may be an effective therapeutic strategy against age-related disorders of hepatic proteostasis. The insignificant decrease in IL6 scores in group $\mathrm{C}$ with trehalose administration could be due to the presence of the trehalase enzyme in the intestinal mucosa, kidneys, liver, and blood in almost all mammals which caused oral trehalose administration to prove inefficient. Other studies have also shown that oral administration of trehalose appears in serum for 4 hours after intake and exerts a therapeutic effect

\section{Conclusion}

Oxidative stress and inflammation are the main mechanisms of the aging process. Trehalose is a natural disaccharide that can increase autophagy activity in various mammalian cells. This study aims to determine the effect of trehalose administration on liver damage through the IL6 expression pathway in old rats. Administration of trehalose sugar in elderly mice affected decreasing the inflammatory factor IL-6. Trehalose also increased AMPK phosphorylation and LC3B-II accumulation in the liver of aged mice. The study could not identify the main target but showed reduced ER UPR activation and inflammatory signaling in aged mice, and prevented an increase in liver injury indices. 


\section{References}

Chronic IL-6 administration desensitizes IL-6 response in liver, causes hyperleptinemia and aggravates steatosis in diet-induced-obese mice. PLoS ONE, 11(6), 1-19. https://doi.org/10.1371/journal.pone.0157956

Gavito, A. L., Bautista, D., Suarez, J., Badran, S., Arco, R., Pavón, F. J., Serrano, A., Rivera, P., Decara, J., Cuesta, A. L., Rodríguez-de-Fonseca, F., \& Baixeras, E. (2016)

Maulina, M. (2018). Zat-Zat yang Mempengaruhi Histopatologi Hepar. In D. Al-Muqsith (Ed.), Unimal Press (Pertama). Unimal Press

Moeini, A., Pedram, P., Makvandi, P., Malinconico, M., \& d'Ayala, G. G. (2020). Wound healing and antimicrobial effect of active secondary metabolites in chitosan-based wound dressings: A review. Carbohydrate polymers, 233, 115839.

Pagliassotti, M. J., Estrada, A. L., Hudson, W. M., Wei, Y., Seals, D. R., Zigler, M. L., Larocca, T. J., Nutrition, H., \& Collins, F. (2017). Trehalose Supplementation Reduces Hepatic Endoplasmic Reticulum Stress and Inflammatory Signaling in Old Mice. J Nutr Biochem, 45, 15-23. https://doi.org/10.1016/j.jnutbio.2017.02.022

Rezabakhsh, A., Rahbarghazi, R., Malekinejad, H., Fathi, F., Montaseri, A., \& Garjani, A. (2019). Quercetin alleviates high glucose-induced damage on human umbilical vein endothelial cells by promoting autophagy. Phytomedicine, 56, 183-193

Susantiningsih, T., \& Mustofa, S. (2018). Ekspresi IL-6 dan TNF- $\alpha$ Pada Obesitas. Jurnal Kedokteran Unila, 2(2), 174-180

Tanner, J. E., \& Alfieri, C. (2021). The fatty acid lipid metabolism nexus in COVID-19. Viruses, 13(1), 90

Tonini, C., Segatto, M., Bertoli, S., Leone, A., Mazzoli, A., Cigliano, L., ... \& Pallottini, V. (2021). Prenatal Exposure to BPA: The Effects on Hepatic Lipid Metabolism in Male and Female Rat Fetuses. Nutrients, 13(6), 1970

Zhang, L., Li, F., Guo, Q., Duan, Y., Wang, W., Yang, Y., ... \& Yin, Y. (2021). Different Proportions of Branched-Chain Amino Acids Modulate Lipid Metabolism in a Finishing Pig Model. Journal of Agricultural and Food Chemistry. 